\title{
Incidence and relevance of QTc-interval prolongation caused by tyrosine kinase inhibitors
}

J S L Kloth*,1,9 , A Pagani ${ }^{2,9}$, M C Verboom ${ }^{3}$, A Malovini ${ }^{4}$, C Napolitano ${ }^{5}$, W H J Kruit ${ }^{1}$, S Sleijfer ${ }^{1,6}$, N Steeghs ${ }^{7}$, A Zambelli ${ }^{8}$ and R H J Mathijssen ${ }^{1}$

${ }^{1}$ Department of Medical Oncology, Erasmus MC Cancer Institute, PO Box 5201, 3075EA Rotterdam, The Netherlands; ${ }^{2}$ Department of Medical Oncology, Fondazione S. Maugeri, Via Maugeri 10, 27100 Pavia, Italy; ${ }^{3}$ Department of Clinical Oncology, Leiden University Medical Centre, PO Box 9600, 2300 RC Leiden, The Netherlands; ${ }^{4}$ Laboratory of Informatics and Systems Engineering for Clinical Research, Salvatore Maugeri Research and Care Institute, Pavia, Italy; ${ }^{5}$ Department of Molecular Cardiology, IRCCS Fondazione S. Maugeri, Via Maugeri 10, 27100 Pavia, Italy; ${ }^{6}$ Cancer Genomics Netherlands, Amsterdam, The Netherlands; 'Department of Medical Oncology, Netherlands Cancer Institute, PO Box 90203, 1006 BE Amsterdam, The Netherlands and ${ }^{8}$ Department of Medical Oncology, Ospedale Papa Giovanni XXIII, P.zza OMS n 1, 24127 Bergamo, Italy

Background: Tyrosine kinase inhibitors (TKIs) are associated with prolongation of the QTc interval on the electrocardiogram (ECG). The QTc-interval prolongation increases the risk of life-threatening arrhythmias. However, studies evaluating the effects of TKIs on QTc intervals are limited and only consist of small patient numbers.

Methods: In this multicentre trial in four centres in the Netherlands and Italy we screened all patients who were treated with any TKI. To evaluate the effects of TKIs on the QTc interval, we investigated ECGs before and during treatment with erlotinib, gefitinib, imatinib, lapatinib, pazopanib, sorafenib, sunitinib, or vemurafenib.

Results: A total of 363 patients were eligible for the analyses. At baseline measurement, QTc intervals were significantly longer in females than in males $\left(Q T c_{\text {females }}=404 \mathrm{~ms} v\right.$ s $Q T c_{\text {males }}=399 \mathrm{~ms}, P=0.027$ ). A statistically significant increase was observed for the individual TKIs sunitinib, vemurafenib, sorafenib, imatinib, and erlotinib, after the start of treatment (median $\triangle \mathrm{QTc}$ ranging from +7 to $+24 \mathrm{~ms}, P<0.004)$. The CTCAE grade for QTc intervals significantly increased after start of treatment $(P=0.0003)$. Especially patients who are treated with vemurafenib are at increased risk of developing a QTc of $\geqslant 470 \mathrm{~ms}$, a threshold associated with an increased risk for arrhythmias.

Conclusions: These observations show that most TKIs significantly increase the QTc interval. Particularly in vemurafenib-treated patients, the incidence of patients at risk for arrhythmias is increased. Therefore, especially in case of combined risk factors, ECG monitoring in patients treated with TKIs is strongly recommended.

Long QT syndrome (LQTS) is a myocardial repolarisation disorder characterised by prolongation of the QT interval on the surface electrocardiogram (ECG). The clinical presentation of LQTS consists of palpitations, syncope, seizures, and sudden cardiac death due to a characteristic arrhythmia known as torsades de pointes (TdP) (El-Sherif and Turitto, 2003; Moss, 2003; Trinkley et al, 2013).

\footnotetext{
*Correspondence: Dr JSL Kloth; E-mail: j.kloth@erasmusmc.nl

This study was presented at the 2014 ASCO Annual Meeting in Chicago, Illinois.

${ }^{9}$ These authors contributed equally to this work.
}

Received 15 September 2014; revised 19 January 2015; accepted 5 February 2015; published online 5 March 2015 
The QT interval represents the total duration of ventricular depolarisation and repolarisation. It is measured on the ECG from the first deflection of the QRS complex to the end of the T-wave. Prolongation of the QT interval usually results from delayed repolarisation. This can be caused by drugs or inherited ion channel abnormalities, which block or result in loss of function of potassium channels (IKr, IKs, and IKl), or opening or gain of function of sodium (Ina) or calcium channels (Grant, 2009). The QT interval is usually corrected for heart rate, leading to the corrected QT interval QTc.

Several factors such as gender, age, electrolyte disturbances, cardiovascular diseases (CVD), and different types of drugs can affect the duration of the QT interval (Yetkin et al, 2001; Benoit et al, 2005). Due to the risk of fatal arrhythmias, the US Food and Drug Administration (FDA) now requires thorough studies to evaluate the potency of new drugs to induce QT-interval prolongation in preclinical and early phase I clinical trials in healthy individuals (El-Sherif and Turitto, 2003). However, for new anticancer drugs these studies are usually not performed in healthy individuals because of their toxicity profile (Curigliano et al, 2008; de Jonge and Verweij, 2008).

As with many drugs, tyrosine kinase inhibitors (TKIs) are reported to prolong the QT interval (Strevel et al, 2007; Bello et al, 2009; Lee et al, 2010; Tolcher et al, 2011; Dogan et al, 2012; Doherty et al, 2013; Dong et al, 2013; Heath et al, 2013; Shah et al, 2013). In vitro studies demonstrated that lapatinib and imatinib interact with the phosphorylation of the cardiac hERG channel. This results in a reduction of the repolarising current (IKr), which can lead to action potential prolongation and subsequent QTinterval prolongation (Lee et al, 2010; Dong et al, 2013).

In a small prospective clinical study to evaluate the cardiac safety of lapatinib in 21 patients, a mean QTc increase of $8.63 \mathrm{~ms}$ was seen (Dogan et al, 2012). In three prospective post-marketing studies in patients with solid tumours treated with sorafenib $(N=31)$, pazopanib $(N=48)$, and sunitinib $(N=24)$ a modest increase of $9.0 \mathrm{~ms}$ of QTc interval with the use of sorafenib, $4.4 \mathrm{~ms}$ after start of pazopanib and $9.6 \mathrm{~ms}$ after start of sunitinib was seen (Bello et al, 2009; Tolcher et al, 2011; Heath et al, 2013).

These drugs have been approved by the FDA because they appear highly effective in situations where treatment options are limited. With an increasing number of TKIs on market, a relatively long on-treatment time, and the application in the adjuvant setting, which is already standard for imatinib in patients with localised GIST with a high risk of relapse, and which is being explored for other TKIs in various tumour types, thorough QTc studies in this group of drugs are necessary to get more insight into their cardiac safety. In this multicentre study performed in four centres in the Netherlands and Italy, we describe the incidence and relevance of QTc-interval prolongation in patients with cancer treated with different types of TKIs.

\section{PATIENTS AND METHODS}

Study design. We undertook a retrospective study in patients with solid malignancies, who were treated with any type of TKI. Patients from four centres in the Netherlands (Erasmus MC Cancer Institute, Rotterdam, Leiden University Medical Centre, Leiden, and Netherlands Cancer Institute-Antoni van Leeuwenhoek, Amsterdam) and Italy (Salvatore Maugeri Foundation, Pavia) were included.

This study was reviewed and approved by the Erasmus MC Medical Ethical Board (MEC 2013-148). All ECGs were obtained as standard clinical care. Demographic and clinical characteristics of the analysed cohort were collected using clinical record forms designed for this study.
Patients were considered eligible if they were aged $\geqslant 18$ years, were treated for solid tumours with any type of TKI and if at least one ECG before start of TKI treatment and one ECG during treatment with TKI were available. Exclusion criteria were as follows: ECGs that do not match criteria for accurate QTc-interval measurements (intra-ventricular conduction delay and/or pacemaker driven rhythm), missing ECGs at baseline or during therapy, and patients with a time-lapse between baseline ECG and start of TKI treatment of more than 1 year. Patients who were subsequently treated with different TKIs were included once. All standard 12-lead ECGs analysed in this study were reviewed by a single expert cardiologist $(\mathrm{CN})$. The QT interval was measured from the beginning of the QRS complex until the point where the deflection of the $\mathrm{T}$ wave crosses the iso-electric line. A description of the statistical method is presented in the Supplementary Material.

Definition of QTc prolongation. Since increases in heart rate result in shortening of the QT interval, a correction for heart rate was applied using the Bazett formula (Sagie et al, 1992):

$$
\mathrm{QTc}=\mathrm{QT} / \sqrt{ } \mathrm{RR}
$$

In this formula, $\mathrm{RR}$ is the interval between two subsequent $\mathrm{R}$ waves. The Bazett formula is the most frequently applied correction in clinical practice, leading to the corrected QT interval or QTc interval (Sagie et al, 1992).

A prolonged QT interval is associated with an increased risk of polymorphic ventricular tachycardia, torsade de pointes (TdP). This study defined a prolonged QT interval corrected for heart rate (QTc) as $\geqslant 470 \mathrm{~ms}$, which represents $<0.5 \%$ of the healthy population (Kobza et al, 2009) and has been shown to be associated with an increased risk of TdP (Trinkley et al, 2013). A clinically relevant increase in QTc $(\Delta \mathrm{QTc})$ was defined as an increase of $\geqslant 30 \mathrm{~ms}$ between a patient's baseline and subsequent ECG as this has also been shown to be associated with increased risk (Li et al, 2010). The QTc was also categorised according to the Common terminology criteria for adverse events (CTCAE) guidelines version 4.03 (grade 0, QTc < 450; grade 1, QTc 450-479 ms; grade 2, QTc 480-499 ms; grade 3, QTc $\geqslant 500 \mathrm{~ms}$; grade 4, QTc $\geqslant 500 \mathrm{~ms}$ with life-threatening signs or symptoms; grade 5, death). Relevant CVD was defined as myocardial infarction and/or heart failure.

Outcome measures used in this study were $(i)$ the quantitative difference in QTc interval between on therapy and baseline ECG measurements ( $\Delta \mathrm{QTc}, \mathrm{ms})$, (ii) the transition from a condition of normal repolarisation to a condition in which QTc is prolonged to an extent with high risk of arrhythmia as a consequence of the TKI therapy (i.e., from QTc $<470$ to QTc $\geqslant 470 \mathrm{~ms}$ ) (Kobza et al, 2009; Trinkley et al, 2013), (iii) clinically relevant $\Delta \mathrm{QTc}$ (defined as $\Delta \mathrm{QTc} \geqslant 30 \mathrm{~ms}$, above which the risk for $\mathrm{TdP}$ is significantly increased) (Li et $a l, 2010$ ) and (iv) QTc-interval CTCAE grade increase during TKI therapy.

\section{RESULTS}

Patient characteristics. A total of 1933 cases of TKI use were screened in this study. In 644 cases at least one ECG before treatment and one ECG during treatment were available. Among these cases, 18 patients were included twice, with subsequent use of different TKIs. One patient had a pacemaker-driven rhythm. In 262 patients, the time lapse between baseline ECG and start of treatment was more than 1 year and patients were therefore excluded from the analysis. The remaining study cohort consisted of 363 patients. The median age at start of treatment was 60 years (interquartile range (IQR) 51-67), and 59\% of patients were male. Sunitinib was the most frequently used TKI in our study cohort, with a total of 110 treated patients. The median QTc interval at baseline visit was $401 \mathrm{~ms}$ (IQR 388-415), where 346 patients 
(95.3\%) had a normal QTc interval (CTCAE grade 0), 14 (3.9\%) had grade 1,2 patients $(0.6 \%)$ had grade 2 , and 1 patient $(0.3 \%)$ had a grade 3 QTc interval. A total number of 37 patients $(10.2 \%)$ had a known history of relevant CVD, while 34 patients $(9.4 \%)$ used co-medication, that can lead to QTc-interval prolongation (Strevel et al, 2007). Patients' demographics and disease characteristics are presented in Table 1.

Variables modulating QTc interval at baseline visit. At baseline measurements, QTc was slightly, but significantly greater in females than in males $\left(\mathrm{QTc}_{\text {females }}=404 \mathrm{~ms}\right.$ (IQR 392-417) vs $\mathrm{QTc}_{\text {males }}=399 \mathrm{~ms}$ (IQR 385-414), $P=0.027$ ), which is consistent with previous studies (Strevel et al, 2007). Patients treated with co-medication known to prolong the QTc interval, such as antidepressants, anti-epileptics, and anti-emetics, had a statistically significant higher baseline QTc interval than the patients who did not use such co-medication (409 ms (IQR 398-424) vs $400 \mathrm{~ms}$ (IQR 387-414), respectively, $P=0.035$ ). Consistent with previous studies, patients suffering from hypokalaemia had longer median QTc intervals than patients with normokalaemia and hyperkalaemia (median QTc in hypokalaemic, normokalaemic, and hyperkalaemic

\section{Table 1. Patient characteristics}

\begin{tabular}{|c|c|}
\hline Variable & $\mathbf{N}(\%)$ or median (IQR) \\
\hline \multicolumn{2}{|l|}{ Gender } \\
\hline Male & $215(59)$ \\
\hline Female & $148(41)$ \\
\hline Age (years) & $60(51-67)$ \\
\hline QTc-interval baseline & $401(388-415)$ \\
\hline QTc-interval therapy & $415(397-431)$ \\
\hline \multicolumn{2}{|l|}{ Tumour type } \\
\hline $\mathrm{RCC}$ & $101(27.8)$ \\
\hline GIST & 49 (13.5) \\
\hline $\mathrm{HCC}$ & $45(12.4)$ \\
\hline Lung cancer & $27(7.4)$ \\
\hline Breast cancer & $16(4.4)$ \\
\hline Melanoma & $69(19.0)$ \\
\hline Other & $56(15.4)$ \\
\hline \multicolumn{2}{|l|}{ Type of TKI } \\
\hline Sunitinib & $110(30.3)$ \\
\hline Vemurafenib & $67(18.5)$ \\
\hline Sorafenib & $52(14.3)$ \\
\hline Pazopanib & $46(12.7)$ \\
\hline Imatinib & $41(11.3)$ \\
\hline Erlotinib & $21(5.8)$ \\
\hline Lapatinib & $16(4.4)$ \\
\hline Gefitinib & $10(2.8)$ \\
\hline \multicolumn{2}{|l|}{ WHO PS baseline } \\
\hline 0 & $155(42.7)$ \\
\hline 1 & $195(53.7)$ \\
\hline 2 & $12(3.3)$ \\
\hline 3 & $1(0.3)$ \\
\hline CVD & $37(10.2)$ \\
\hline QTc co-medications & $34(9.4)$ \\
\hline \multicolumn{2}{|l|}{ Race } \\
\hline Caucasian & $349(96.1)$ \\
\hline Other & $14(3.5)$ \\
\hline \multicolumn{2}{|l|}{ Site } \\
\hline EMC & $184(50.7)$ \\
\hline $\mathrm{NKI}$ & $118(32.5)$ \\
\hline LUMC & $54(14.9)$ \\
\hline SMF & $7(1.9)$ \\
\hline
\end{tabular}

Abbreviations: $C V D=$ cardiovascular disease; $E M C=$ Erasmus $\mathrm{MC}$-Cancer Institute; GIST = gastro-intestinal stromal tumour; HCC = hepatocellular carcinoma; LUMC = Leiden University Medical Centre; NKI= Netherlands Cancer Institute—Antoni van Leeuwenhoek; $\mathrm{RCC}=$ renal cell cancer; $\mathrm{SMF}=$ Salvatore Maugeri Foundation; $\mathrm{TKI}=$ tyrosine kinase inhibitor; WHO PS = World Health Organisation performance score. patients $416 \mathrm{~ms}$ (IQR 376-431), $401 \mathrm{~ms}$ (IQR 389-415), and $391 \mathrm{~ms}$ (IQR 381-408), $P=0.028$, respectively). A more detailed report about baseline QTc intervals according to the evaluated variables is found in Supplementary Table 1.

Quantitative variations of the QTc interval. The median on treatment time before the ECG was performed was 43 days (IQR 26-118 days). In the entire population of 363 patients, the start of a TKI resulted in a statistically significant increase in QTc interval, with a median $\Delta \mathrm{QTC}$ of $+11 \mathrm{~ms}(P<0.00001)$. The distribution of $\triangle$ QTc was significantly different across TKIs $(P=0.0001)$. When analysing subgroups of patients treated with specific TKIs, patients treated with sunitinib $(N=110)$, vemurafenib $(N=67)$, sorafenib $(N=52)$, imatinib $(N=41)$, and erlotinib $(N=21)$ showed a statistically significant increase in QTc interval after start of treatment (median $\Delta \mathrm{QTc}$ ranging from +7 to $+24 \mathrm{~ms}, P<0.004$; Figure 1). For lapatinib $(N=16)$ and pazopanib $(N=46)$, no statistically significant increase in QTc interval after start of treatment was found (Table 2).

Increase in CTCAE grade and prevalence of high-risk patients. A statistically significant increase in CTCAE grade for QTc intervals was observed after start of TKI therapy in the whole cohort $(P=0.0003)$. In detail, 33 patients $(9.1 \%)$ were characterised by an increased CTCAE grade. Of these, 31 passed from grade 0 to grade $\geqslant 1$, while the remaining 2 individuals passed from grade 1 to grade 2 or 3 . Of the remaining patients, $321(88.4 \%)$ did not have an increase or decrease in CTCAE grade after start of TKI treatment, while 9 patients $(2.5 \%)$ had a reduced CTCAE grade for QTc interval (Table 3).

Similarly, a statistically significant increase in the prevalence of high-risk patients was observed after TKI therapy start (QT $c_{\text {baseline }}$ $\geqslant 470 \mathrm{~ms}=1.7 \%$ vs $\left.\mathrm{QTc}_{\text {therapy }} \geqslant 470 \mathrm{~ms}=5.8 \%, P=0.005\right)$, with 20 individuals (5.5\%) who transitioned from a low-risk to a highrisk condition. Moreover, 5 patients (1.4\%) developed QTc $\geqslant 500$ ms (CTCAE grade 3) after therapy start, and 76 patients $(20.9 \%)$ experienced a clinically relevant QTc increase after TKI start. All five patients who developed QTc $\geqslant 500 \mathrm{~ms}$ after start of therapy had a $\Delta Q T c$ of $\geqslant 100 \mathrm{~ms}$.

When focusing on specific TKI subgroups, we observed that individuals treated with vemurafenib $(N=67)$ were characterised by a statistically significant increase both in terms of CTCAE grade for QTc intervals $(P=0.008)$ and in the probability of becoming

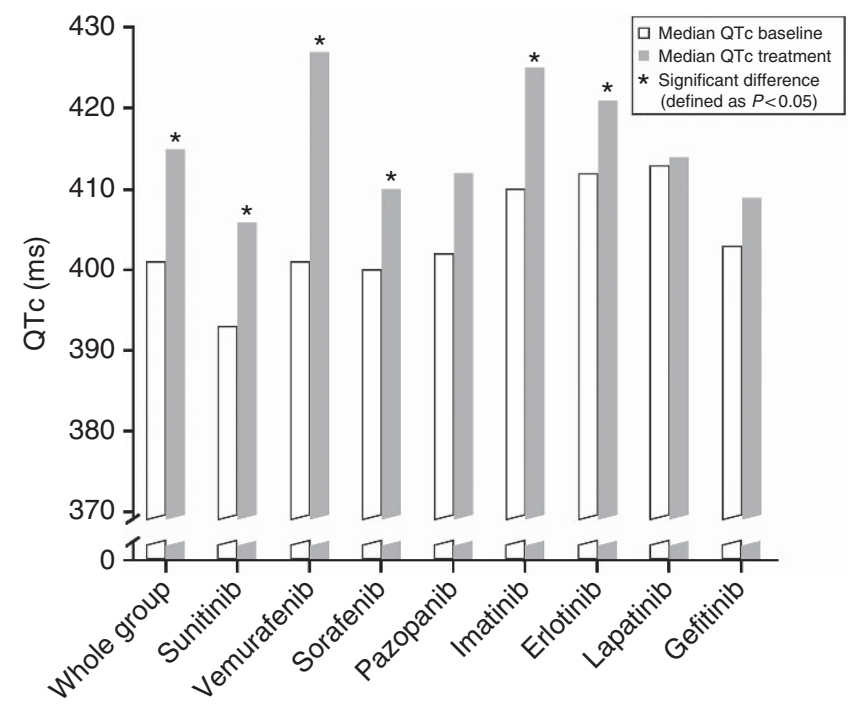

Figure 1. $\triangle \mathrm{QTc}$ in the whole cohort and in specific TKIs. Blue bars represent the median baseline QTc interval and red bars represent the median QTc interval during treatment. At the y axis, the QTc interval is expressed in $\mathrm{ms}$. 
high-risk patients $(P=0.023)$, also showing the greatest probability of clinically relevant QTc increase (34.3\%). No statistically significant variations in the evaluated outcomes were observed in the other TKI subgroups.

Characterisation of TKI-induced QTc variability. The median age of patients who had a worsening of the CTCAE grade for QTc interval was significantly higher than that of patients who did not (62 years (IQR 59-72) vs 60 years (IQR 51-67), respectively, $P=0.023)$. These patients also more often suffered from hypokalaemia $(20.7 \%$ vs $3.1 \%, P=0.0009$; Table 4$)$. Multivariate logistic regression confirmed that age and hypokalaemia were independent predictors of worsened CTCAE grade for QTc interval $\quad(\mathrm{OR}=1.10, \quad 95 \% \quad \mathrm{CI}=1.05-1.16, \quad P=0.0002 \quad$ and $\mathrm{OR}=10.30,95 \% \mathrm{CI}=2.22-4.64, P=0.002$ ).

Similarly, patients who had QTc prolongation to $\geqslant 470 \mathrm{~ms}$ after start of TKI treatment were significantly older than patients who did not (66 years (IQR 60-76) and 60 years (IQR 51-66), respectively, $P=0.007)$ and were more frequently treated with QTc-prolonging co-medication ( $25 \%$ vs $8.5 \%, P=0.030)$. This was confirmed by multivariate logistic regression $(\mathrm{OR}=1.10,95 \%$ $\mathrm{CI}=1.04-1.15, P=0.0004$ and $\mathrm{OR}=4.38,95 \% \mathrm{CI}=1.14-15.25$, $P=0.023)$.

We did not identify variables that have a statistically significant impact on quantitative $\Delta \mathrm{QTC}$ or on the probability of clinically relevant $\Delta$ QTc (Supplementary Table 2).

Table 2. TKI-induced change in QTc interval

\begin{tabular}{|l|c|c|c|c|} 
& \multicolumn{5}{|c|}{$\begin{array}{c}\text { OTc interval (ms) } \\
\text { Median (IQR) }\end{array}$} \\
\hline TKI & $\mathbf{n}$ & Baseline & Therapy & P-value \\
\hline Whole & 363 & $401(388-415)$ & $415(397-431)$ & $<0.00001$ \\
\hline Sunitinib & 110 & $393(380-410)$ & $406(390-424)$ & $<0.00001$ \\
\hline Vemurafenib & 67 & $401(394-417)$ & $427(415-442)$ & $<0.00001$ \\
\hline Sorafenib & 52 & $400(386-412)$ & $410(394-425)$ & 0.0004 \\
\hline Pazopanib & 46 & $402(390-411)$ & $412(395-431)$ & 0.079 \\
\hline Imatinib & 41 & $410(396-424)$ & $425(410-439)$ & 0.002 \\
\hline Erlotinib & 21 & $412(398-430)$ & $421(414-440)$ & 0.004 \\
\hline Lapatinib & 16 & $413(405-423)$ & $414(397-428)$ & 0.982 \\
\hline Gefitinib & 10 & $403(396-417)$ & $409(390-429)$ & 0.919 \\
\hline $\begin{array}{l}\text { Abbreviations: IQR= interquartile range; } n=\text { number of patients within each TKI group; } \\
\Delta \text { QTc=median difference between QTc interval during TKI treatment and QTc interval at } \\
\text { baseline; TKI=tyrosine kinase inhibitor. Bold values are statistically significant. }\end{array}$ \\
\hline
\end{tabular}

\section{DISCUSSION}

We found a significant increase in QTc intervals after start of treatment with sunitinib, vemurafenib, sorafenib, imatinib, and erlotinib. In most cases, the increase in QTc interval is only modest and under normal conditions not clinically relevant. However, in 76 of the 363 patients the start of TKI treatment resulted in a clinically relevant increase of the QTc interval of $\geqslant 30 \mathrm{~ms}$. The incidence of high-risk patients, defined as QTc $\geqslant 470 \mathrm{~ms}$ (Trinkley et al, 2013), increased during treatment with a TKI. Still, only the subgroup receiving vemurafenib showed a statistically significant increase in the number of patients with QTc $>470 \mathrm{~ms}$.

In the entire cohort, $21 \%$ of patients showed a clinically relevant increase in QTc of $\geqslant 30 \mathrm{~ms}$ with TKI treatment, but as most had a normal baseline QTc interval, only $5 \%$ had a QTc of $\geqslant 470 \mathrm{~ms}$, which is associated with increased risk of arrhythmias. Although older patients, patients with low potassium and patients taking comedication which can prolong the QTc interval are at higher risk of QTc-interval prolongation, it is still not possible to differentiate which patient is at risk at the start of treatment.

Therefore, treating physicians should anticipate this possible increase in QTc intervals and perform ECGs during treatment with TKI, and be aware of symptoms, such as palpitation, seizures, and collapse, which may be the result of drug-induced LQTS. In those diseases where alternative treatment is available, such as in metastatic renal cell carcinoma where sunitinib and pazopanib have equivalent efficacy (Motzer et al, 2013), consideration should be given to use a TKI with less QTc prolongation effects if the QTc is prolonged at baseline or develops during treatment.

Furthermore, many patients use co-medication during TKI treatment. As drugs of a broad variety are known for drug-induced QTc-interval prolongation, it is likely that patients use several drugs which can lead to QTc-interval prolongation and thereby intensifying the effect on the QTc interval. This was shown in this study, where 14 patients (4\%) using such co-medication were more likely to develop QTc prolongation. In those cases, extra awareness may be necessary and switching to drugs that are not likely to have an effect on QTc interval should be considered.

This study has several limitations. This was a retrospective study in patients treated with cancer, and therefore in most cases ECGs were not performed at predefined times before, during, and after TKI therapy. Since fluctuations in QTc interval are frequent and may be caused by many factors (Yetkin et al, 2001; Benoit et al, 2005), this is a weakness of our study, and may have influenced outcome (Molnar et al, 1996). Also, only patients treated with a

Table 3. Increase in CTCAE grade and prevalence of high-risk patients

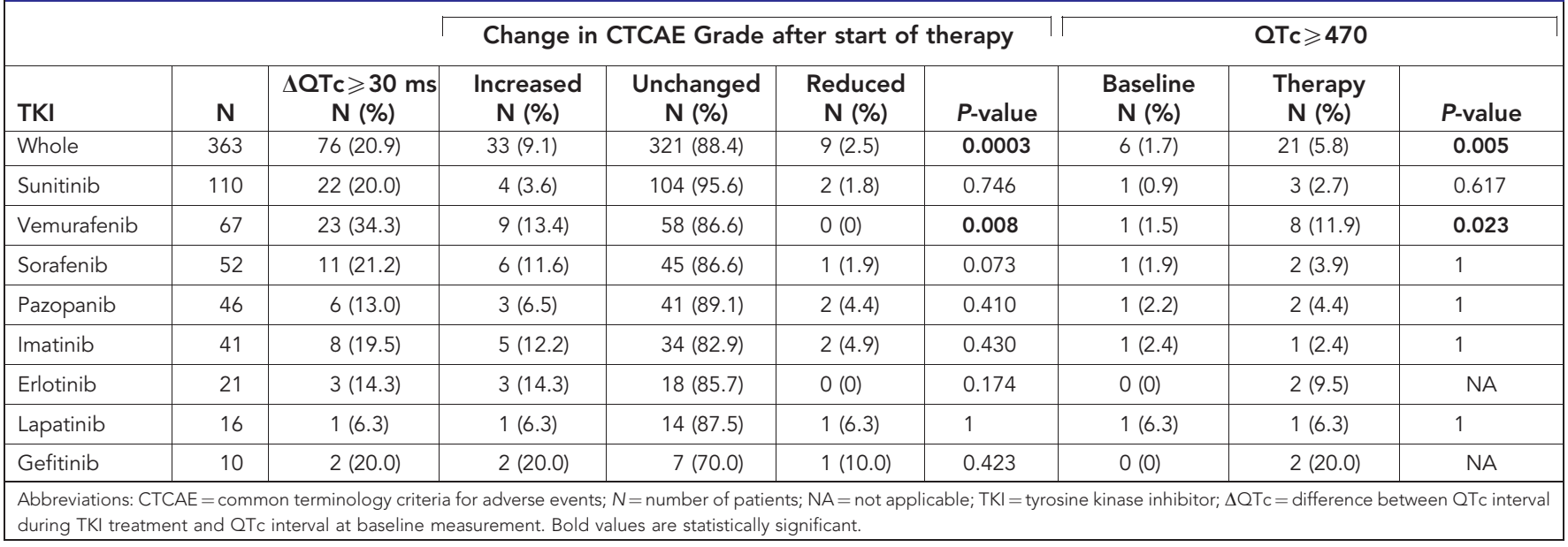


Table 4. Variables influencing CTCAE grade for QTc interval and the probability to become a high-risk patient

\begin{tabular}{|c|c|c|c|c|c|c|c|}
\hline \multirow[b]{2}{*}{ Variable } & \multirow[b]{2}{*}{$\mathbf{N}$} & \multicolumn{3}{|c|}{ CTCAE grade during TKI } & \multicolumn{3}{|c|}{ Transition to high risk (QTc $\geqslant 470 \mathrm{~ms}$ ) } \\
\hline & & $\begin{array}{c}\text { Increased }(n=33) \\
\text { median }(I Q R) \\
\text { or } N(\%) \\
\end{array}$ & $\begin{array}{c}\text { Unchanged/Reduced }(\mathrm{n}=330) \\
\text { median }(\mathrm{IQR}) \\
\text { or } \mathrm{N}(\%)\end{array}$ & $P$-value & $\begin{array}{l}\text { Yes }(\mathrm{n}=20) \\
\text { median (IQR) } \\
\text { or } \mathrm{N}(\%)\end{array}$ & $\begin{array}{l}\text { No }(n=343) \\
\text { median (IQR) } \\
\text { or } N(\%)\end{array}$ & $P$-value \\
\hline Age (years) & 363 & $62(59-72)$ & $60(51-67)$ & 0.026 & $66(60-76)$ & $60(51-66)$ & 0.007 \\
\hline \multicolumn{8}{|l|}{ Gender } \\
\hline $\begin{array}{l}\text { Males } \\
\text { Females }\end{array}$ & $\begin{array}{l}215 \\
148\end{array}$ & $\begin{array}{l}22(66.7) \\
11(33.3)\end{array}$ & $\begin{array}{l}193(58.5) \\
137(41.5)\end{array}$ & 0.458 & $\begin{array}{r}14(70) \\
6(30)\end{array}$ & $\begin{array}{l}201(58.6) \\
142(41.4)\end{array}$ & 0.358 \\
\hline \multicolumn{8}{|c|}{ Co-medication } \\
\hline $\begin{array}{l}\text { Yes } \\
\text { No }\end{array}$ & $\begin{array}{r}34 \\
329\end{array}$ & $\begin{array}{r}6(18.2) \\
27(81.8)\end{array}$ & $\begin{array}{c}28(8.5) \\
302(91.5)\end{array}$ & 0.107 & $\begin{array}{r}5(25) \\
15(75)\end{array}$ & $\begin{array}{c}29(8.4) \\
314(91.6)\end{array}$ & 0.030 \\
\hline \multicolumn{8}{|l|}{ CVD } \\
\hline $\begin{array}{l}\text { Yes } \\
\text { No }\end{array}$ & $\begin{array}{r}37 \\
326 \\
\end{array}$ & $\begin{array}{r}5(15.2) \\
28(84.9)\end{array}$ & $\begin{array}{c}32(9.7) \\
298(90.3)\end{array}$ & 0.360 & $\begin{array}{r}4(20) \\
16(80)\end{array}$ & $\begin{array}{c}33(9.6) \\
310(90.4)\end{array}$ & 0.134 \\
\hline \multicolumn{8}{|l|}{ DM } \\
\hline $\begin{array}{l}\text { Yes } \\
\text { No }\end{array}$ & $\begin{array}{r}43 \\
320 \\
\end{array}$ & $\begin{array}{c}3(9.1) \\
30(90.9)\end{array}$ & $\begin{array}{r}40(12.1) \\
290(87.9)\end{array}$ & 0.782 & $\begin{array}{c}1(5) \\
19(95)\end{array}$ & $\begin{array}{r}42(12.2) \\
301(87.8)\end{array}$ & 0.489 \\
\hline \multicolumn{8}{|l|}{$\mathrm{Ca}^{2+}$} \\
\hline $\begin{array}{l}\text { Normo/Hyper } \\
\text { Hypo }\end{array}$ & $\begin{array}{r}169 \\
70\end{array}$ & $\begin{array}{r}13(61.9) \\
8(38.1)\end{array}$ & $\begin{array}{r}156(71.6) \\
62(28.4)\end{array}$ & 0.451 & $\begin{array}{l}8(80) \\
2(20)\end{array}$ & $\begin{array}{r}161(70.3) \\
68(29.7) \\
\end{array}$ & 0.728 \\
\hline \multicolumn{8}{|l|}{$\mathbf{K}^{+}$} \\
\hline $\begin{array}{l}\text { Normo/Hyper } \\
\text { Hypo }\end{array}$ & $\begin{array}{r}304 \\
15 \\
\end{array}$ & $\begin{array}{r}23(79.3) \\
6(20.7) \\
\end{array}$ & $\begin{array}{c}281(96.9) \\
9(3.1) \\
\end{array}$ & 0.0009 & $\begin{array}{r}16(88.9) \\
2(11.1) \\
\end{array}$ & $\begin{array}{c}288(95.7) \\
13(4.3) \\
\end{array}$ & 0.204 \\
\hline
\end{tabular}

TKI were included and there was no control group given non-TKI treatment in which the variation in the QTc interval could be examined. Furthermore, there may be a bias in patient selection since patients with cardiac events may be more likely to have had ECGs performed. Patients who died from arrhythmia may not have been included in analyses when no ECGs were available. One patient taking a TKI in the study died suddenly. This did not occur in a hospital and no cause of death was reported so it is unknown whether this was related to QTc-interval prolongation. Possible effects from electrolyte disorders on the QTc interval may have been missed, because of missing data. However, we showed in a large group of patients treated with TKIs that there is an overall increase in QTc interval after start of treatment, which may possibly be harmful for patients treated with these drugs. Future prospective studies could improve the current knowledge about TKI-induced QTc prolongation.

Overall, we may conclude that most TKIs tend to cause an increase in QTc intervals. In some cases, this increase is clinically relevant, and therefore the QTc interval should be verified in patients before starting TKI treatment and during therapy. Monitoring QTc intervals during TKI treatment is particularly important in patients with a history of QTc-interval prolongation, in patients using co-medication which can prolong the QTc interval, in patients with electrolyte disorders, and in patients with pre-existing CVD. Furthermore, during treatment with TKIs physicians should be aware of clinical symptoms, which may be attributed to QTc-interval prolongation.

\section{REFERENCES}

Bello CL, Mulay M, Huang X, Patyna S, Dinolfo M, Levine S, Van Vugt A, Toh M, Baum C, Rosen L (2009) Electrocardiographic characterization of the QTc interval in patients with advanced solid tumors: pharmacokineticpharmacodynamic evaluation of sunitinib. Clin Cancer Res 15: 7045-7052.
Benoit SR, Mendelsohn AB, Nourjah P, Staffa JA, Graham DJ (2005) Risk factors for prolonged QTc among US adults: Third National Health and Nutrition Examination Survey. Eur J Cardiovasc Prev Rehabil 12: 363-368.

Committee for Proprietary Medicinal Products (CPMP). Points to consider: The Assessment of the Potential for QT Interval Prolongation by nonCardiovascular Medicinal Products, Vol. 1997. The European Agency for the Evaluation of Medicinal Products: London, UK.

Common Terminology Criteria for Adverse Events (CTCAE), Version 4.03. U.S. Department of Health and Human Services; National Institutes of Health, National Cancer Institute, published 14 June 2010.

Curigliano G, Spitaleri G, Fingert HJ, de Braud F, Sessa C, Loh E, Cipolla C, De Pas T, Goldhirsch A, Shah R (2008) Drug-induced QTc interval prolongation: a proposal towards an efficient and safe anticancer drug development. Eur J Cancer 44: 494-500.

de Jonge M, Verweij J (2008) QTc prolongation and/or oncology drug development: who's in danger? Eur J Cancer 44: 486-487.

Dogan E, Yorgun H, Petekkaya I, Ozer N, Altundag K, Ozisik Y (2012) Evaluation of cardiac safety of lapatinib therapy for ErbB2-positive metastatic breast cancer: a single center experience. Med Oncol 29: 3232-3239.

Doherty KR, Wappel RL, Talbert DR, Trusk PB, Moran DM, Kramer JW, Brown AM, Shell SA, Bacus S (2013) Multi-parameter in vitro toxicity testing of crizotinib, sunitinib, erlotinib, and nilotinib in human cardiomyocytes. Toxicol Appl Pharmacol 272: 245-255.

Dong Q, Fu XX, Du LL, Zhao N, Xia CK, Yu KW, Cheng LX, Du YM (2013) Blocking of the human ether-a-go-go-related gene channel by imatinib mesylate. Biol Pharm Bull 36: 268-275.

El-Sherif N, Turitto G (2003) Torsade de pointes. Curr Opin Cardiol 18: $6-13$.

Grant AO (2009) Cardiac ion channels. Circ Arrhythm Electrophysiol 2: $185-194$.

Heath EI, Infante J, Lewis LD, Luu T, Stephenson J, Tan AR, Kasubhai S, LoRusso P, Ma B, Suttle AB, Kleha JF, Ball HA, Dar MM (2013) A randomized, double-blind, placebo-controlled study to evaluate the effect of repeated oral doses of pazopanib on cardiac conduction in patients with solid tumors. Cancer Chemother Pharmacol 71: 565-573. 
Kobza R, Roos M, Niggli B, Abacherli R, Lupi GA, Frey F, Schmid JJ, Erne P (2009) Prevalence of long and short QT in a young population of 41,767 predominantly male Swiss conscripts. Heart Rhythm 6: 652-657.

Lee HA, Kim EJ, Hyun SA, Park SG, Kim KS (2010) Electrophysiological effects of the anti-cancer drug lapatinib on cardiac repolarization. Basic Clin Pharmacol Toxicol 107: 614-618.

Li EC, Esterly JS, Pohl S, Scott SD, McBride BF (2010) Drug-induced QT-interval prolongation: considerations for clinicians. Pharmacotherapy 30: 684-701.

Molnar J, Zhang F, Weiss J, Ehlert FA, Rosenthal JE (1996) Diurnal pattern of QTc interval: how long is prolonged? Possible relation to circadian triggers of cardiovascular events. J Am Coll Cardiol 27: 76-83.

Moss AJ (2003) Long QT Syndrome. JAMA 289: 2041-2044.

Motzer RJ, Hutson TE, Cella D, Reeves J, Hawkins R, Guo J, Nathan P, Staehler M, de Souza P, Merchan JR, Boleti E, Fife K, Jin J, Jones R, Uemura H, De Giorgi U, Harmenberg U, Wang J, Sternberg CN, Deen K, McCann L, Hackshaw MD, Crescenzo R, Pandite LN, Choueiri TK (2013) Pazopanib versus sunitinib in metastatic renal-cell carcinoma. $N$ Engl J Med 369: 722-731.

Sagie A, Larson MG, Goldberg RJ, Bengtson JR, Levy D (1992) An improved method for adjusting the QT interval for heart rate (the Framingham Heart Study). Am J Cardiol 70: 797-801.
Shah RR, Morganroth J, Shah DR (2013) Cardiovascular safety of tyrosine kinase inhibitors: with a special focus on cardiac repolarisation (QT interval). Drug Saf 36: 295-316.

Strevel EL, Ing DJ, Siu LL (2007) Molecularly targeted oncology therapeutics and prolongation of the QT interval. J Clin Oncol 25: 3362-3371.

Tolcher AW, Appleman LJ, Shapiro GI, Mita AC, Cihon F, Mazzu A, Sundaresan PR (2011) A phase I open-label study evaluating the cardiovascular safety of sorafenib in patients with advanced cancer. Cancer Chemother Pharmacol 67: 751-764.

Trinkley KE, Page 2nd RL, Lien H, Yamanouye K, Tisdale JE (2013) QT interval prolongation and the risk of torsades de pointes: essentials for clinicians. Curr Med Res Opin 29: 1719-1726.

Yetkin E, Senen K, Ileri M, Atak R, Topaloglu S, Ergun K, Yanik A, Tandogan I, Cehreli S, Duru E, Demirkan D (2001) Diurnal variation of QT dispersion in patients with and without coronary artery disease. Angiology 52: 311-316.

This work is published under the standard license to publish agreement. After 12 months the work will become freely available and the license terms will switch to a Creative Commons AttributionNonCommercial-Share Alike 4.0 Unported License.

Supplementary Information accompanies this paper on British Journal of Cancer website (http://www.nature.com/bjc) 